\title{
ESTADO VACINAL, TIPO DE HABITAÇÃO E NIVEL CULTURAL DA MÃE E SUA RELAÇÃO COM O ESTADO IMUNITÁRIO À POLIOMIELITE, EM UMA AMOSTRA DE ESCOLARES DO MUNICIPIO DE SÃO PAULO, BRASIL.
}

Victório Barbosa*

Klaus E. Stewien**

Cornélio P. Rosenburg**:

Barbosa, V. et al. Estado vacinal, tipo de habitação e nivel cultural da mãe e sua relaçào com o estado imunitário à poliomielite, em luma amostra de escolares do municipio de Sáo Paulo, Brasil. Rev. Saúde públ., S. Paulo. $11: 330-7,1977$.

RESUMO: Foram determinados numa amostra probabilistica da população escolar do 1" grau da rede da Prefeitura Municipal de São Paulo: (1) o estado vacinal das crianças - no de doses de vacina de Sabin - (2) o tipo de sua habitação - residência, favela e cortiço - e (3) o nivel cultural da mãe analfabeta e alfabetizada. Estes fatores foram relacionados com a presença de anticorpos protetores e o estado imunitário da mesma população infantil. Os resultados mostraram a existência de uma correlação entre a presença de antlcorpos protetores contra os poliovirus dos tipos 1,2 e 3 e o número de doses de vacina oral (trivalente) recebidas pelas crianças de 7 e 8 anos de idade. Contudo, as crianfas só mostraram niveis satisfatórios de imunidade com 5 e mais doses de vacina. Nos grupos etários de 9 a 15 e mais anos, o estado imunitário das crianças não se apresentou mais relacionado com o número de doses de vacina recebidas, o que deve ser atribuido à imunização das crianças não vacinadas através de infeç̧ōes naturais com poliovirus, que circulam nas comunidades. Quando o estado imunitário das crianças foi relacionado com o tipo de sua habitação e o nivel cultural da mâe, verificou-se que quantidades substancialmente menores de vacina oral, administradas às crianças cujas mães sāo analfabetas, ou que habitam em favelas e cortiços, foram até certo ponto compensadas, em termos de imunidade, através de infeç̧oses naturais com poliovirus circulantes. Os autores recomendam um esquema de vacinação contra a poliomielite que apresente, em sua série básica, pelo menos 5 doses de vacina de Sabin (trivalente).

Unitermos: Inquéritos sorológicos, escolares. Poliomielite, São Paulo, Brasil. Imunidade. Vacinação. Vacina Sabin.

* Do Departamento de Epidemiologia da Faculdade Saúde Pública da USP -. Av. Dr. Arnaldo, 715 - Săo Paulo, SP - Brasil

* Do Departamento de Microbiologia e Imunologia do Instituto de Ciências Biomédicas da USP - setor Saúde Públicas - Av. Dr. Arnaldo, 715 - São Paulo, SP - Brasil.

** Do Departamento de Saúde Materno-Infantil da Faculdade de Saúde Pública da USP - Av. Dr. Arnaldo, 715 - São Paulo, SP - Brasil. 
BARBOSA. V. et al. Estado vacinal. tipo de habitação e nível cultural da mãe e sua relação com o estado imunitário à poliomielite, e m uma amostra de escolares do município de de São Paulo. Brasil. Rev. Saude púbt., S. Paulo, 11:330-7. 1977.

\section{INTRODUCCAO}

Em trabalho anterior 14 foram publicados os resultados de um estudo soro-epidemiológico de uma população de escolares do 1.0 grau, sendo apresentados a prevalência de anticorpos protetores e os níveis de imunidade à poliomielite. O referido estudo foi subvencionado pelo Departamento de Assistência Escolar da Secretaria da Educação da Prefeitura Municipal de São Paulo e os resultados basearam-se numa amostra representativa dos alunos do $1^{\circ}$ grau da Rede Escolar Municipal. O estudo mostrou que, de um modo geral, os niveis de imunidade foram insuficientes nas 3 zonas gengráficas consideradas - "Centro", "Intermediária" e "Periférica" - assim como nas 13 Regionais Administrativas da Prefeitura, ficando aquém dos niveis desejáveis de $75 \%$ de indivíduos triplo-imunes.

O presente trabalho, que complementa aquele, tem a finalidade de elucidar melhor a questão dos niveis de imunidade relativamente baixos que foram encontrados na maioria dos grupos etários anteriormente examinados (7 a 15 anos). Para tanto, 0 estado imunitário da população escolar foi relacionado com (1) o estado vacinal das crianças (2) com o tipo de sua habitação e (3) com o nível educacional da mãe.

\section{MATERIAL E METODOS}

Em trabalho anterior (Stewien e col. ${ }^{14}$ 1977) foram detalhadamente descritos o plano de estudo, a população das crianças examinadas, sua amostragem probabilistica, assim como a coleta e a apuração das informaçĩes prestadas, a colheita das amostras de sangue e os métodos utilizados para a determinação dos anticorpos neutralizantes.

Em resumo, mediante a utilização de um processo sistemático de amostragem de classes, obteve-se uma amostra representa- tiva da população de alunos da Rede Escolar da Prefeitura Municipal de São Paulo. Desta amostra foram obtidas, numa primeira etapa, as informações necessárias para o estudo de 1.559 crianças, o que representa $96,7 \%$ do total da amostra casual. Os questionários foram preenchidos por quatro grupos integrados por educadoras e professoras especialmente treinadas. As informações foram prestadas pelas mães ou responsáveis das crianças. $O$ histórico vacinal foi também obtido, em pequeno número de casos, pela caderneta de vacinação.

Para a pesquisa de anticorpos protetores foram colhidas, numa segunda etapa, amostras de sangue por extração digital, que foram imediatamente remetidas ao laboratório. As provas de neutralização foram realizadas segundo a microtécnica 9 . Foi possível obter resultados completos de um total de 1.489 crianças, o que representa $95,5 \%$ do total de crianças das çuais se obteve as informaçōes necessárias ao presente estudo.

\section{RESULTADOS E DISCUSSÃO}

\section{Niveis de imunidade e vacinação oral}

A Tabela 1 apresenta o estado vacinal da população infantil estudada, segundo o número de doses de vacina oral trivalente recebidas pelas crianças. Verifica-se que, embora $85,9 \%$ das crianças tenham tomado a vacina oral, somente $63,7 \% \quad(38,4 \%$ $+25,3 \%$ ) receberam a série básica de 3 doses e apenas $25,3 \%$ obtiveram imunização completa de 5 doses de vacina, das quais duas doses de reforço.

Admite-se, com base em trabalhos anteriores que, em paises de clima tropical e sub-tropical, a criança está adequadamente imunizada desde que tenha recebido pelo menos 3 doses básicas de vacina Sabin (trivalente) 2.12.15. Estes mesmos trabalhos mostraram que, para efeito de contro- 
BARBOSA, V. et al. Estado vacinal, tipo de habitação e nível cultural da mãe e sua relação com o estado imunitário à poliomielite, em uma amostra de escolares do município de de São Paulo, Brasil. Rev. Saúde públ., S. Paulo, 11:330-7, 1977.

TA B E L A 1

Histórico vacinal das crianças da população escolar do $1^{9}$ grau da l'ede da Prefeitura Municipal de São Paulo-1974.

\begin{tabular}{ccc}
\hline $\begin{array}{c}\text { No de } \\
\text { doses }\end{array}$ & No & $\%$ \\
\hline 0 & 211 & 14,1 \\
1 e 2 & 333 & 22,2 \\
3 e 4 & 576 & 38,4 \\
5 e + & 381 & 25,3 \\
\hline Total & 1.501 & 100,0 \\
\hline
\end{tabular}

le da doença, pelo menos $75 \%$ da população dos grupos etários deve ter sido vacinado, de modo correto, com essas 3 doses de vacina, pois, assim, estarão esses grupos imunes contra a doença. Nestas condições, é de se ver que a população em estudo, segundo o histórico vacinal apresentado, é deficiente quanto ao número de doses básicas recebidas, pois somente $63,6 \%$ receberam as 3 doses, o que, como vimos, está açuém do mínimo desejável de $75 \%$.
Embora os dados apresentados na Tabela 1, na maioria das vezes, não se baseiam na caderneta de vacinação e, sim na informação da mãe ou responsável pela criança, parecem-nos, em grande parte, fidedignas estas informações por dois motivos. Primeiro, porque a vacina Sabin é a única administrada por via oral, o que permite aos pais ou responsáveis distinguí-las das demais vacinas, facilitando fixar na memória as aplicações dessa vacina em seus filhos. Em segundo lugar, esta suposição confirma-se pelo que podemos observar na Tabela 2 , em que se nota uma estreita correlação entre o estado vacinal e o estado imunitário das crianças da população examinada.

Verifica-se, nessa Tabela, que a prevalência de anticorpos aumenta proporcionalmente, para os 3 tipos de virus, com o número de doses de vacina aplicadas. A relação proporcional entre estado imunitário e estado vacinal certamente não teria sido observada se as informações prestadas subre o número de doses de vacina não fossem em sua maioria corretas. As crianças que não receberam nenhuma dose de vacina se imunizaram através de infecção

T A B F L A 2

Prevalência de anticorpos neutralizantes contra os poliovírus dos tipos 1,2 e 3 nos escolares de 7 e 8 anos de idade, da rede da Prefeitura Municipal de São Paulo, segundo o número de doses de vacina oral (trivalente) administradas - 1974.

\begin{tabular}{|c|c|c|c|c|c|c|}
\hline \multirow{3}{*}{$\begin{array}{c}\text { No de doses de vacina } \\
\text { oral trivalente }\end{array}$} & \multicolumn{6}{|c|}{ Prevalencia de anticorpos } \\
\hline & \multicolumn{2}{|c|}{ TIPO 1} & \multicolumn{2}{|c|}{ TIPO 2} & \multicolumn{2}{|c|}{ TIPO : } \\
\hline & No & $\%$ & $\mathrm{Na}$ & $\%$ & No & $\%$ \\
\hline 0 & $18 / 32$ & 56.3 & $25 / 32$ & 78,1 & $9 / 32$ & 28.1 \\
\hline $1+2$ & $86 / 44$ & 59.1 & $32 / 44$ & 75,0 & $25 / 44$ & 56,8 \\
\hline $3+4$ & $92 / 1: 1$ & 70,2 & $108 / 1: 31$ & 82.4 & $82 / 131$ & 62,6 \\
\hline 5 e + & $87 / 111$ & 78.8 & $101 / 111$ & 91,0 & $77 / 111$ & 69,4 \\
\hline
\end{tabular}


BARBOSA, V. et al. Estado vacinal, tipo de habitação e nível cultural ra mảe e sua relação com o estado imunitário à poliomielite, e $m$ uma amostra de escolares do município de de São Paulo, Brasil. Rev. Saúde públ., S. Paulo, 11:330-7, 1977.

natural com os virus da poliomielite. Estas infecçōes podem ter sido em decorrência do contato com poliovirus naturais, que ainda circulam em nosso meio, ou com os virus atenuados de Sabin, eliminados pelas crianças que receberam a vacina.

$\dot{E}$ interessante ubservar que a imunidade das crianças vacinadas somente alcança niveis satisfatórios a partir de 5 doses de vacina ural. A presença do tipo 2 chega a alcançar um nivel superior a $90 \%$ e, 1 , tipo 1, quase $80 \%$. Apenas a imunidade contra o tipo 3 fica aquém do nivel minimo desejável de $75 \%$, o que deve ser atribuido à capacidade imunogênica menor do virus atenuado Leon $12 a_{1} b$ da vacina Sabin, causando, muitas vezes, niveis séricus de anticorpos extremamente baixos. $5,7,8,10,13,15$.

Os resultados do presente trabalho concordam com os encontrados em recente estudo realizado em Vellore, na India, en que as taxas de suro-conversaao das crianças, de 6 a 51 semanas de idade, somente alcançaram niveis elevados de imunidade a partir da $5^{*}$ dose de vacina oral trivalente administrada. 6 o fato foi atribuido a uma resistência temporária das urianças à "pega" vacinal, devido a um fato, que veremos a seguir. Estes resultados certamente contrastan com aqueles encontrados em paises altamente desenvolvidus e de clima temperado, onde duas nu três doses de vacina são suficientes para se atingir niveis de imunidade acima dos $90 \%$, contra os 3 tipos de virus da poliomielite.

Con a finalidade de encontrar as causas que determinam as baixas taxas cie soroconversãn e, conseqüentemente, niveis insuficientes de imunidade em regiñes de clima quente e em urupos populacionais de precárias condiçóes de vicla, a Organização Mundial da Saúde fez realizar recentemente ampla investigação em Uganda, na África ${ }^{3}$ A equipe de pesquisadores póde então demonstrar a existència de una substância inibidora no aparelho digestivo das crianças que receberam a vacina oral de Sabin e não apresentaram "pega" vacinal. Foi observado yue o inibidor impede a implantação e a multiplicação dos vírus atenuados na mucosa intestinal, sendo responsável pelo maior número das falhas vacinais verificadas. Coube à interferência viral, ocasionada por enterovírus dos grupos Coxsackie e ECHO, un papel menor na yuestão destas falhas. O mesmo estudo mostrou que os efeitos antagônicos do inibidor e da interferência viral podem ser superados na prática da vacinação, por meio da administração de repetidas doses de vacina.

En face ao que for exposto, e preciso recomendar, para efeitus práticos, um esquema de vacinação contra a poliomielite que seja constituido, em sua série hásica, de pelo menos 5 doses de vacina oral trivalente, modificando conceito até então existente de que eram suficientes, nesses casos, apenas 3 doses básicas. Além disto, doses de reforço deven ser administradas em espaços adequados de tempo, para se manterem elevados os niveis de imunidade nas comunidades nas yuais se introduziu a vacinação oral.

O aumento proporcional da imunidade, cuntra us 3 tipos de poliovírus, anteriormente observado nas crianças nos grupos etários de 7 e 8 anos, não foi mais verificado nas de 9 e mais anos de idade, como mostra a Tabela 3, onde são apresentados sumariamente os resultados referentes aos grupos etários de a a 15 e mais anos. A mais provável explicação deste fato é de yue um numero apreciável de crianças não vacinadas se imunizaran através do contato que tiveram com poliovirus naturais, que ainda circulam em nossa comunidade, ou com os vírus atenuados de Sabin, eliminados pelos grupos vacinados. 
BARBOSA. V. et al. Estado vacinal, tipo de habıtação e nivel cultural da mãe e sua relação com o estado imunitário à poliomielite. e $m$ uma amostra de escolares do município de de São Paulo, Brasil. Rer. Saúde pübl, S. Paulo, 11:330-7. 197 t.

T A B E L A :3

Provaléncia de anticorpos neutralizantes contra os poliovirus dos tipos 1. 2 e 3 nos escolares de 9-15 e + anos de idade. da rede da Prefeitura Municipal de Sảo Paulo, segundo o número de doses de racina oral (trivalente) administradas - 1974.

\begin{tabular}{|c|c|c|c|c|c|c|}
\hline \multirow{3}{*}{$\begin{array}{c}\text { Nu de doses de racina } \\
\text { oral trivalente }\end{array}$} & \multicolumn{6}{|c|}{ Prevalència de anticorpos neutralizantes } \\
\hline & \multicolumn{2}{|c|}{ TIPO 1} & \multicolumn{2}{|c|}{ TIPO 2} & \multicolumn{2}{|c|}{ TIPO :3 } \\
\hline & $N:$ & $\%$ & $\mathrm{No}$ & $\%$ & No & $\%$ \\
\hline 11 & $144 / 177$ & 81.4 & $142 / 177$ & 81,0 & $124 / 177$ & 70.1 \\
\hline $1+2$ & $237 / 287$ & 82,5 & $230 / 287$ & 80.9 & $196 / 287$ & 68.3 \\
\hline $3+4$ & $349 / 44$ & 78,8 & $377 / 44$ & 86.0 & $28: 3 / 443$ & $6 ? .9$ \\
\hline 5 e + & $190 / 255$ & 74.5 & $218 / 255$ & 85.5 & $158 / 255$ & 62.0 \\
\hline
\end{tabular}

\section{Vacinaçào oral e tipo de habitação} das crianças

Na Tabela 4 são comparados os niveis de imunidade, em termos de crianças duplo mais triplo imunes, da população escolar estudada, de acordo com os três tipos de habitação em que as crianças vivem: residência, favela e cortiço. Os resultados referentes à favela e cortiço não mostraram diferenças significativas e, assim, foram reunidos, como mostra a referida tabela.

É preciso salientar, inicialmente, que o grupo de crianças que mora en residências teve uma cobertura vacinal muito superior àquele que vive em favelas e cortiços, pois c) primeiro grupo possui a alta percentagem de $79,9 \%$ de crianças que receberan 3 ou mais doses de vacina $(838$ crianças divididas por 1.269 ) contra apenas $43,8 \%$ do segundo grupo mencionado (63 crianças divididas por 144). Entretanto, isto não se reflete nos niveis de imunidade, que foram respectivamente $77,9 \%$ e $81,3 \%$ de crianças duplo mais triplo imunes (a diferença não é estatisticamente significante, pelo teste do $X^{2}$ ao nivel de $\left.p \geqslant 0,05\right)$. No caso especifico das crianças que receberam uma e duas doses de vacina, foi até observada uma diferença estatisticamente significante, ao nivel de $p \geqslant 0,05$, a favor do grupo de crianças que vivem nas favelas e cortiços.

Admitindo-se, na melhor das hipoteses, que a vacinação oral seja igualmente eficaz em crianças residentes em favelas e cortiços ou em residências, somos levados a acreditar que a semelhança entre os niveis de imunidade desses dois grupos, apesar da sua diferença quanto ao estado vacinal, seja resultado de um maior numero de infecções naturais ocasionadas pelos virus da poliomielite nas crianças que vivem em favelas e cortiços do que nas que moram em residências, o que obviamente se reflete nos niveis de imunidade. Esta hipótese e sustentada pelo fato de ser mais intensa a circulação de vírus em populações de precárias condições de vida e saneamento e de alta promiscuidade, como diversos estudos puderam mostrar +.11.16.

\section{Vacinação oral e nivel cultural da mãe}

A Tabela 5 apresenta os niveis de imunidade, en termos de crianças duplo mais triplo imunes, da populaçāo escolar estu- 
BARBOSA, V, et al. Estado vacinal, tipo de habitação e nível cultural da mãe e sua relação com o estado imunitário à poliomielite, em uma amostra de escolares do municipio de de São Paulo, Brasil. Rev. Saúde públ., S. Paulo, 11:330-7, 1977.

\section{T A B E L A 4}

Niveis de imunidade à poliomielite, em termos de individucs duplo mais triplo imunes, da população escolar do $1^{9}$ grau da rede da Prefeitura Municipal de São Paulo. segundo o número de doses de vacina oral recebidas e o tipo de habitação - 1974 .

\begin{tabular}{|c|c|c|c|c|}
\hline \multirow[b]{2}{*}{$\begin{array}{c}\text { Tipo } \\
\text { de } \\
\text { habitação }\end{array}$} & \multicolumn{4}{|c|}{ Níveis de imunidades } \\
\hline & $\begin{array}{c}0 \\
\text { dose }\end{array}$ & $\begin{array}{l}1 \text { e } 2 \\
\text { doses }\end{array}$ & $\begin{array}{l}3 \text { e }+ \\
\text { doses }\end{array}$ & Total \\
\hline $\begin{array}{c}\text { Favela } \\
\mathrm{e}\end{array}$ & $16 / 22^{*}$ & $52 / 59$ & $49 / 63$ & $117 / 144$ \\
\hline Cortiço & $72,7 \%$ & $88,1 \%$ & $77.8 \%$ & $81,3 \%$ \\
\hline \multirow{2}{*}{ Residência } & $134 / 186$ & $184 / 245$ & $670 / 838$ & $988 / 1269$ \\
\hline & $72,0 \%$ & $75,1 \%$ & $80,0 \%$ & $77,9 \%$ \\
\hline
\end{tabular}

* Número de duplo + triplo imunes divididos pelo número de crianças examinadas.

TA B E L A 5

Níveis de imunidade à poliomielite. em termos de individuos duplo mais triplo imunes da população escolar do $1^{\circ}$ grau da Prefeitura Municipal de São Paulo. segundo o número de doses de vacina oral recebidas e o nivel educacional da mãe - 1974.

\begin{tabular}{|c|c|c|c|c|}
\hline \multirow[b]{2}{*}{$\begin{array}{l}\text { Nivel } \\
\text { cultural } \\
\text { da mãe }\end{array}$} & \multicolumn{4}{|c|}{ Niveis de imunidade } \\
\hline & $\begin{array}{c}0 \\
\text { dose }\end{array}$ & $\begin{array}{l}1 \text { e } 2 \\
\text { doses }\end{array}$ & $\begin{array}{c}3 \mathrm{e}+ \\
\text { doses }\end{array}$ & Total \\
\hline \multirow{2}{*}{ Analfabeta } & $107 / 148^{*}$ & $170 / 210$ & $388 / 475$ & $665 / 833$ \\
\hline & $72.3 \%$ & $80.9 \%$ & $81.7 \%$ & $79,8 \%$ \\
\hline \multirow{2}{*}{ Alfabetizada } & $43 / 60$ & $66 / 92$ & $381 / 426$ & $440 / 578$ \\
\hline & $71,6 \%$ & $71,7 \%$ & $77,7 \%$ & $77.1 \%$ \\
\hline
\end{tabular}

* Número de duplo + triplo imunes divididos pelo número de crianças examinadas.

dada, segundo o numero de doses de vacina administrada e o nivel educacional da mãe. Como se poderia esperar, a cobertura vacinal foi muito melhor nas crianças de mães alfabetizadas do que nas crianças de mães analfabetas. As percentagens de crianças que receberam 3 e mais doses de vacina foram, respectivamente, 73,7\% (426 crianças divididas por 578) e 57,0\% (475 crianças divididas por 833). Entretanto, os niveis de imunidade observados no grupo de crianças de mães alfabetizadas foram surpreendentemente semelhantes aos niveis verificados no grupo de crianças de mães analfabetas (as diferenças não são estatisticamente significantes, ao nivel de $p \geqslant 0,05$ - teste do $\mathrm{X}^{2}$.

Partindo da hipótese de que a vacinação oral tenha a mesma eficácia nos dois grupos examinados, somos levados a concluir que os hábitos de higiene são mais precários nas crianças de mães analfabetas do 
BARBOSA, V, et al. Estado vacinal, tipo de habitação e nível cultural da mãe e sua relação com o estado imunitário à poliomielite, e $\mathrm{m}$ uma amostra de escolares do município de de São Paulo, Brasil. Rev. Saúde pübl., S. Paulo, 11:330-7, 1977.

que nas de mães alfabetizadas. Em conseqüência disto, as crianças de mães analtabetas tem contato mais freqüente com enterovirus, aumentando com isto o número de infeç̧ōes naturais com os virus da poliomielite, o que acaba se refletindo nos niveis de imunidade das crianças. Um estudo recente realizado em Israel mostrou que a circulação de enterovírus é mais intensa em crianças de mães com nivel cultural baixo do que em crianças de mães com nivel cultural elevado. ${ }^{15} \mathrm{~A}$ mesma investigação mostrou também que uma maior circulação de enterovírus dos grupos Coxsackie e ECHO se reflete negativamente nas taxas de suro-conversão através do fenômeno da interferência viral, havendo a neces- sidade de aplicar um número maior de doses neste grupo de crianças para obter niveis de imunidade elevados. Consequientemente, no presente estudo as crianças de mães analfabetas deveriam apresentar níveis de imunidade muito inferiores às de mães alfabetizadas, primeiramente devido a diferença significativa do número de doses a favor das crianças deste último grupo e, em segundo lugar, devido a uma maior circulação de enterovírus no primeiro grupo. Sendo, entretanto, surpreendentemente semelhantes os niveis encontrados, somos levados a admitir a hipótese antes apresentada, ou seja, de que as crianças de mães analfabetas se imunizaram em parte por infecçóes naturais, causadas pelos poliovirus circulantes em seu ambiente.

RSPU-B/364

BARBOSA, V. et al. [Relation of the vaccination status, housing and cultural level of the mother to the immune status to poliomyelitis in a sample of school children from the City of S. Paulo, Brazil.] Rev. Saúde públ., S. Paulo, 11: 330-7, 1977.

ABSTRACT: In a probabilistic sample of the elementary school children belonging to the S. Paulo public school system, a survey was conducted in order to establish 1) the vacination status of the children - number of doses of oral polio vaccine, 2) the kind of housing - private home or slum, 3) the cultural status of the mother - literate or illiterate. These factors were studied in relation to the prevalence of neutralizing antibodies and the immune status to poliomyelitis of those children. The results showed a correlation between the presence of type 1,2 and 3 poliovirus antihodies and the number of doses of trivalent Sabin vaccine fed to children 7 and 8 years old, who exibited satisfactory immunity level only with 5 and more doses of the vaccine. In the age group of 9 to 15 years and higher, the immune status of the children was no more related to the number of doses of the vaccine which is considered as a result of the immunization of the children $b y$ means of natural infections with curculating polioviruses. When the immune status of the children was related to housing and the cultural level of the mother, the relationship described for certain age groups ( 7 and 8 years) was not observed, which seems to be explained by the same reasons refered to the 9 to 15 and higher age groups. The authors recommended that the primary course of immunization for infants should consist of at least 5 doses of trivalent Sabin vaccine.

Uniterms: Serological surveys, school children. Poliomyelitis, S. Paulo, Brazil. Immunity. Poliovirus vaccine, oral. 
BARBOSA. V. et al. Estado vacinal, tipo de habitação e nível cultural da mãe e sua relação com o estado imunitário à poliomielite, e $\mathrm{m}$ uma amostra de escolares do município de de São Paulo. Brasil. Rer. Saũde públ., S. Paulo, 11:330-7, 1977.

\section{REFERENCIAS BIBLIOGRÁFICAS}

1. BARBOSA. V. \& STEWIEN, K.E. Estado imunitário relativo à poliomielite das crianças de $0-12$ anos, residentes no município de São Paulo, Brasil e assistidas pelo Hospital Menino Jesus. Rer. Saude puibl., S. Paulo, 9:137-5:3, 1975 .

2. COckBURN, W.C. Poliomyelitis raccination in tropical countries. Adrancexp. med.Biol., $31: 223-36,1972$.

3. DöMöK, I. et al. Factors effecting the efficacy of live poliovirus raccine in warm climates. Bull.Wld Hith Org., $51: 333-47,1974$.

4. FELDMAN, R.A. et al, Oral poliovirus raccination in children: a study suggesting enterovirus interference. Pediatrics, 33:526-33, 1964.

5. GOLD, E. et al, Immune status of children one to four years of age as determined by history and antibody measurement. New Engl. J. Med., 289:231-5, 1973.

6. JOHN, T.J. Antibody response of infants in tropics to five doses of oral polio raccine. Brit, Med. J., 1:312, $19 \% 6$.

7. LAMB, G.A. \& FELDMAN, H.A. Rubella raccine responses and other viral antibodies in Syracuse children. Amer. $J$. Dis. Child, 122:117-21, 1971.

8. LENNARTZ, H. \& FISCHER, K. Überwachung der Poliomyelitis-Verbreitung in Hamburg. Arch. Hyg., Berl., $\mathbf{3 5 1}$ 757,1967

9. LENNETTE, E.H. \& SCHMIDT, N.J., ed. Diagnostic procedures for viral and rickttsial diseases. 4th ed. New York, American Public Health Association, 1969.
10. IINNEMANN, C.C. et al. Poliovirus antibody in urban school children. $J$. Pediat,, 84:404-6, 1974.

11. RAMOS ALVAREZ, M. Poliomyelitis. In: INTERNATIONAL CONFERENCE ON VACCINES AGAINST VIRAL AND RICKETTSIAL DISEASES OF MAN, 1st. Washington, D.C., 1966. Washington, D.C., Pan American Health Organization, 1967. p. 213-4. (PAHOScient. publ., 147).

12. RAMOS E ALVAREZ, $M$, et al. Use of Sabin's live poliovirus vaccine in Mexico: results of a large scale trial, in live poliovirus raccines. In: INTERNATIONAL CONFERENCE ON LIVE POLIOVIRUS VACCINE, 2nd, Washington, D.C., 1960. Papers presented. Washington, D.C., Pan American Health Organization, 1960. p. 368-409. (PAHO-Scient. publ., 50).

13. RASMUSSEN, C.M. et al. Inadequate poliovirus immunity levels in immunized Illinois chuldren. Amer. J. Dis. Child, 126:465-9, 1973.

14. Stewien, K.E. et al, Níveis de imunidade contra a poliomielite em uma amostra de escolares do municipio de São Paulo, Brasil. Rev. Saúde públ., S. Paulo, $11: 270-8,1977$.

15. SWARTZ, T.A. et al, Routine administration of oral polio vaccine in a subtropical area: factores possibly influencing sero-conversion rates, $J$. Hyg., London, 70:719-26, 1972.

16. SWARTz T.A. et al. Non-polio virus interference with oral polio raccine immunization: possible influence of phrsical climate and socio-economic status, Adranc. exp. med. Biol., 31: $237-40,1972$.

Recebido para publucação em 08/12/1976 A provado para publicação em 17/12/1976 